\title{
Application of RCM Reaction in the Construction of ABC Ring of Micrandilactone A
}

\author{
Yandong Zhang, Yefeng Tang, Tuoping Luo, Juan Shen, Jiahua Chen* and Zhen Yang* \\ Key Laboratory of Bioorganic Chemistry and Molecular Engineering of Ministry of Education, College of \\ Chemistry, State Key Laboratory of Natural and Biomimetic Drugs, School of Pharmaceutical Science, and \\ Laboratory of Chemical Genomics, Shenzhen Graduate School, Peking University, Beijing, 100871
}

zyang@chem.pku.edu.cn

\section{Supporting information}

\section{Experimental Section}

\section{General Information}

The boiling point of petroleum ether is between $60-90{ }^{\circ} \mathrm{C}$. Silica gel (200-300 mesh) for purification was purchased from Qing Dao Hai Yang Chemical Industry Co. of China. ${ }^{1} \mathrm{H}-\mathrm{NMR}$ and ${ }^{13} \mathrm{C}-\mathrm{NMR}$ were recorded at $300 \mathrm{MHz}$ and $75 \mathrm{MHz}$ with Varian Mercury 300 spectrometer or at $400 \mathrm{MHz}$ and $100.6 \mathrm{MHz}$ with Brucker ARX400 spectrometer. Mass spectrometric data were obtained using ZAB-HS mass spectrometer.

All non-aqueous reactions were carried out in flame-dried glassware under an argon atmosphere, unless otherwise noted. All solvent were reagent grade. Diethyl ether $\left(\mathrm{Et}_{2} \mathrm{O}\right)$, tetrahydrofuran (THF) and benzene were freshly distilled from sodium/benzophenone ketyl under argon. Dichloromethane was distilled from $\mathrm{CaH}_{2}$. Cerium (III) Chloride was dried at $140{ }^{\circ} \mathrm{C}$ under vacuum for 3 hours before use. All other commercial reagents used as received. 


\section{Experimental procedure and spectral data}

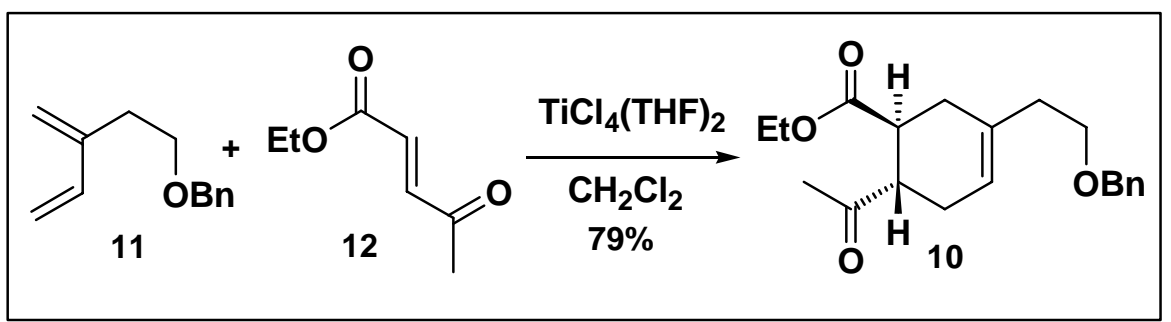

Compound 10: To a solution of diene $11(15.9 \mathrm{~g}, 84.5 \mathrm{mmol})$ and keto-ester $12(5.4 \mathrm{~g}, 42$ mmol) in anhydrous $\mathrm{CH}_{2} \mathrm{Cl}_{2}(150 \mathrm{~mL})$ was added $\mathrm{TiCl}_{4} \cdot \mathrm{THF}_{2}(2.8 \mathrm{~g}, 8.4 \mathrm{mmol})$ at $0{ }^{\circ} \mathrm{C}$, and the mixture was stirred at r.t. for two days. The mixture was quenched with $\mathrm{NH}_{4} \mathrm{Cl}$ solution $(50 \mathrm{~mL})$ and extracted with $\mathrm{CH}_{2} \mathrm{Cl}_{2}(3 \times 60 \mathrm{ml})$. The combined organic layers were washed with brine $(2 \mathrm{x}$ $15 \mathrm{~mL}$ ), and dried over $\mathrm{Na}_{2} \mathrm{SO}_{4}$. The solvent was removed under vacuum and the residue was purified by $\mathrm{SiO}_{2}$ flash chromatography (petroleum ether/ethyl acetate $=8 / 1$ ) to give product $\mathbf{1 0}$ as a light yellow oil (11.1 g, 79\%).

${ }^{1}$ H-NMR $\left(300 \mathrm{MHz}, \mathrm{CDCl}_{3}\right): \delta$ 7.38-7.23 (m, 5H), 5.48-5.46 (m, 1H), $4.5(\mathrm{~s}, 2 \mathrm{H})$, 4.15-4.07 (q, $J=7.2 \mathrm{~Hz}, 2 \mathrm{H}), 3.55-3.50(\mathrm{t}, J=6.6 \mathrm{~Hz}, 2 \mathrm{H}), 3.05-2.75(\mathrm{~m}, 2 \mathrm{H}), 2.43-2.35(\mathrm{~m}, 1 \mathrm{H})$, 2.33-2.29 (t, $J=6.6 \mathrm{~Hz}, 2 \mathrm{H}), 2.23(\mathrm{~s}, 3 \mathrm{H}), 2.19(\mathrm{~m}, 3 \mathrm{H}), 1.26-1.20(\mathrm{t}, J=7.2 \mathrm{~Hz}, 3 \mathrm{H}) ;{ }^{13} \mathrm{C}-\mathrm{NMR}$ $\left(75 \mathrm{MHz}, \mathrm{CDCl}_{3}\right): \delta 210.9,175.0,138.1,133.6,128.2,127.5,127.5,127.4,120.1,72.7,68.3,48.0$, 41.3, 37.0, 31.3, 28.9, 27.7, 13.9; LRMS (EI): $\mathrm{m} / \mathrm{z} 330$.

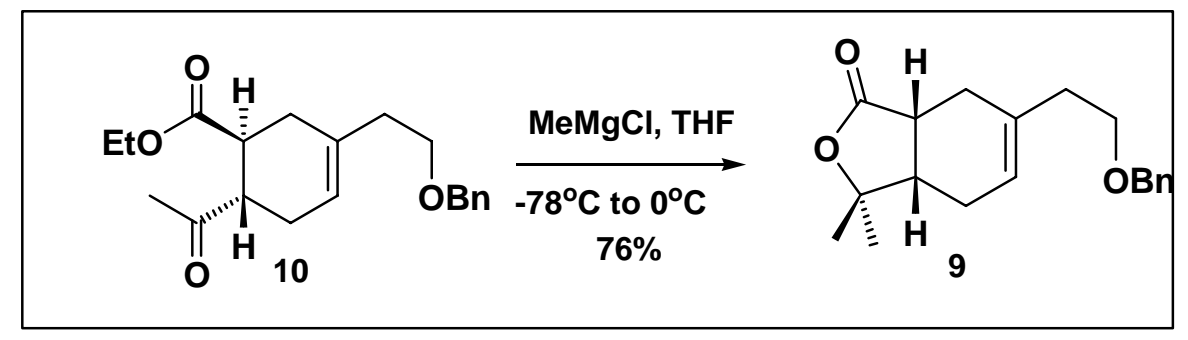

Compound 9: To a solution of the keto-ester obtained above ( $30.5 \mathrm{~g}, 93 \mathrm{mmol})$ in THF $(250 \mathrm{~mL})$ was added methyl magnesium chloride $(3.0 \mathrm{M}$ in THF, $33.9 \mathrm{~mL}, 102 \mathrm{mmol})$ in dropwise at $-78{ }^{\circ} \mathrm{C}$, and the mixture was stirred at $-78^{\circ} \mathrm{C}$ for $3 \mathrm{~h}$, and then $0{ }^{\circ} \mathrm{C}$ for another $3 \mathrm{~h}$. The reaction was quenched with aq. $\mathrm{HCl}(1 \mathrm{~N}, 110 \mathrm{~mL})$ at $0{ }^{\circ} \mathrm{C}$, and the mixture was extracted with ether $(3 \mathrm{x}$ $100 \mathrm{~mL})$. The combined organic layers were washed with brine $(2 \times 15 \mathrm{~mL})$, and the organic layer was dried over $\mathrm{Na}_{2} \mathrm{SO}_{4}$. The solvent was removed under vacuum and the residue was purified by $\mathrm{SiO}_{2}$ flash chromatography (petroleum ether/ethyl acetate $=8 / 1$ ) to give product $\mathbf{9}$ as a colorless oil (21.2 g, 76\%).

${ }^{1}$ H-NMR (300MHz, $\mathrm{CDCl}_{3}$ ): $\delta$ 7.38-7.27 (m, 5H), 5.55-5.54 (dd, $\left.J=3.3 \mathrm{~Hz}, 1.2 \mathrm{~Hz}, 1 \mathrm{H}\right)$, $4.51(\mathrm{~s}, 2 \mathrm{H}), 3.56-3.52(\mathrm{t}, J=6.6 \mathrm{~Hz}, 2 \mathrm{H}), 2.46-2.39(\mathrm{~m}, 2 \mathrm{H}), 2.36-2.32(\mathrm{t}, J=6.6 \mathrm{~Hz}, 2 \mathrm{H})$, 2.17-2.11 (m, 2H), 2.07-1.96 (m, 2H), $1.46(\mathrm{~s}, 3 \mathrm{H}), 1.27$ (s, 3H); ${ }^{13} \mathbf{C}-\mathbf{N M R}\left(75 \mathrm{MHz}, \mathrm{CDCl}_{3}\right): \delta$ 176.3, 137.9, 134.6, 128.0, 127.4, 127.3, 121.4, 85.5, 72.6, 68.0, 47.5, 40.4, 37.2, 28.7, 27.2, 25.5, 20.7; LRMS (EI): $\mathrm{m} / \mathrm{z} 300$. 


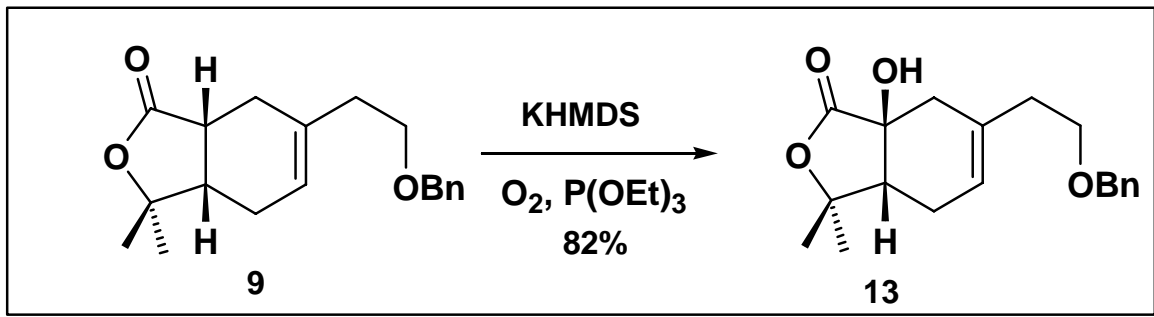

Compound 13: To the solution of lactone 9 (3 g, $10 \mathrm{mmol})$ in anhydrous THF $(30 \mathrm{~mL})$ was added potassium bis(trimethylsilyl)amide $(0.5 \mathrm{M}$ in toluene, $26.0 \mathrm{ml}, 13 \mathrm{mmol})$ in dropwise under $\mathrm{N}_{2}$ at $-78{ }^{\circ} \mathrm{C}$, and the mixture was stirred at $-78{ }^{\circ} \mathrm{C}$ for $30 \mathrm{~min}$. and then at $0{ }^{\circ} \mathrm{C}$ for an additional hour. After addition of few drops of $\mathrm{P}(\mathrm{OEt})_{3}$, the $\mathrm{N}_{2}$ atmosphere was replaced by $\mathrm{O}_{2}$, and the mixture was continually stirred at $0{ }^{\circ} \mathrm{C}$ under $\mathrm{O}_{2}$ for 3 hours. The reaction was carefully quenched with aq. $\mathrm{HCl}$, and then extracted with ether $(3 \times 30 \mathrm{~mL})$. The combined organic extracts were washed with brine $(2 \times 10 \mathrm{~mL})$, and dried over $\mathrm{Na}_{2} \mathrm{SO}_{4}$. The solvent was removed under vacuum and the residue was purified by $\mathrm{SiO}_{2}$ flash chromatography (petroleum ether/ethyl acetate $=2 / 1)$ to give product 13 as a light yellow oil $(2.6 \mathrm{~g}, 82 \%)$, which was solidified for standing at room temperature.

${ }^{1}$ H-NMR $\left(300 \mathrm{MHz}, \mathrm{CDCl}_{3}\right): \delta$ 7.37-7.22 (m, 5H), 5.62-5.60 (m, 1H), $4.47(\mathrm{~s}, 2 \mathrm{H})$ 3.57-3.50 (t, $J=6.6 \mathrm{~Hz}, 2 \mathrm{H}), 2.49-2.32$ (comp. m, 6H), 2.11-1.98 (m, 1H), 1.44 (s, 3H), 1.22 (s, $3 \mathrm{H}) ;{ }^{13}$ C-NMR $\left(75 \mathrm{MHz}, \mathrm{CDCl}_{3}\right): \delta 178.7,138.0,130.9,128.2,127.5,127.4,120.8,84.7,73.9$, 72.7, 68.0, 47.3, 37.2, 36.2, 29.9, 22.3, 21.2; LRMS (EI): $\mathrm{m} / \mathrm{z} 316$.

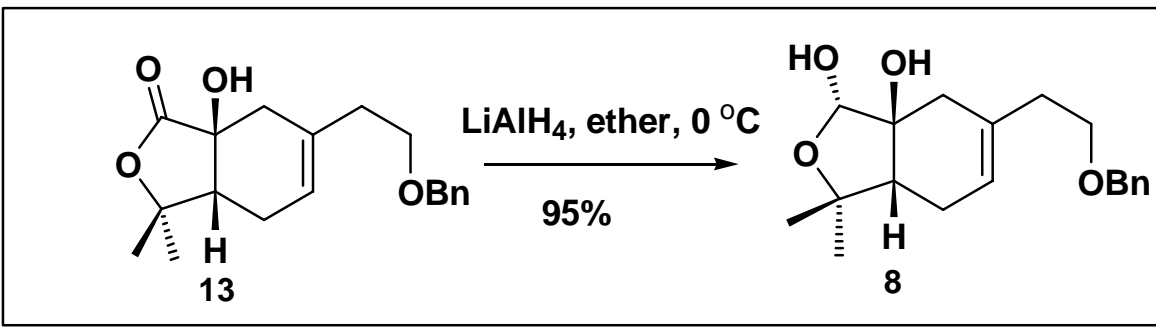

Compound 8: To the solution of hydroxyl lactone $13(1.9 \mathrm{~g}, 6 \mathrm{mmol})$ in anhydrous ether $(20 \mathrm{~mL})$ was added $\mathrm{LiAlH}_{4}(0.23 \mathrm{~g}, 6 \mathrm{mmol})$ at $0{ }^{\circ} \mathrm{C}$ in one portion, and the mixture was stirred at the same temperature for $1.5 \mathrm{~h}$. The reaction was quenched with a saturated $\mathrm{NH}_{4} \mathrm{Cl}$ solution $(5$ $\mathrm{mL})$, the mixture was extracted with ether $(3 \mathrm{x} 10 \mathrm{~mL})$. The combined organic layers were washed with brine $(2 \times 5 \mathrm{~mL})$, and dried over $\mathrm{Na}_{2} \mathrm{SO}_{4}$. The solvent was removed under vacuum and the residue was passed through a silica gel pad, and washed with EtOAc. The filtrate was concentrated and the residue was pure enough for the next step without purification.

${ }^{1}$ H-NMR $\left(300 \mathrm{MHz}, \mathrm{CDCl}_{3}\right): \delta$ 7.36-7.25 (m, 5H), 5.56-5.55 (m, 1H), $4.87(\mathrm{~s}, 1 \mathrm{H}), 4.49$ $(\mathrm{s}, 2 \mathrm{H}), 3.58-3.53(\mathrm{t}, J=6.6 \mathrm{~Hz}, 2 \mathrm{H}), 2.39-2.21(\mathrm{~m}, 4 \mathrm{H}), 2.20-2.15(\mathrm{~m}, 2 \mathrm{H}), 2.00-1.94(\mathrm{~m}, 1 \mathrm{H})$, $1.34(\mathrm{~s}, 3 \mathrm{H}), 1.13(\mathrm{~s}, 3 \mathrm{H}) ;{ }^{13} \mathrm{C}-\mathbf{N M R}\left(75 \mathrm{MHz}, \mathrm{CDCl}_{3}\right): \delta 138.1,130.9,128.2,127.5,127.4,120.8$, 98.7, 83.0, 76.5, 72.7, 68.4, 46.0, 37.7, 35.2, 32.3, 23.8, 21.3; LRMS (EI): m/z 318 . 


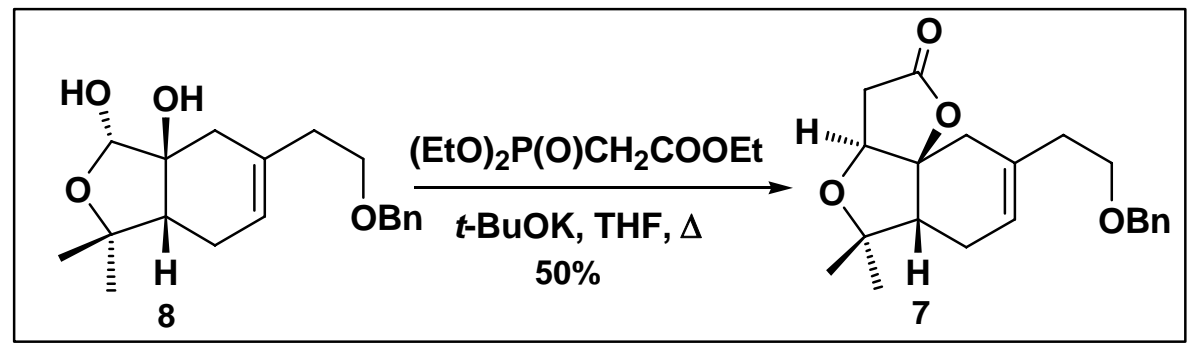

Compound 7: To the solution of triethyl phosphonoacetate $(3.57 \mathrm{ml}, 18 \mathrm{mmol})$ in THF $(30 \mathrm{~mL})$ was added t-BuOK $(2.0 \mathrm{~g}, 18 \mathrm{mmol})$ at $25{ }^{\circ} \mathrm{C}$, and the mixture was stirred at the same temperature for $2 \mathrm{~h}$. After addition of compound $8(1.9 \mathrm{~g}, 6 \mathrm{mmol})$ in THF $(10 \mathrm{~mL})$, the mixture was heated at $80{ }^{\circ} \mathrm{C}$ for $24 \mathrm{~h}$. The reaction was quenched with $\mathrm{NH}_{4} \mathrm{Cl}$ solution $(10 \mathrm{~mL})$, and the mixture was extracted with ether $(3 \times 20 \mathrm{~mL})$. The combined organic layers were washed with brine $(2 \times 5 \mathrm{~mL})$, and dried over $\mathrm{Na}_{2} \mathrm{SO}_{4}$. The solvent was removed under vacuum and the residue was purified by $\mathrm{SiO}_{2}$ flash chromatography (petroleum ether/ethyl acetate $=4 / 1$ ) to give product 7 as a light yellow oil $(1.1 \mathrm{~g}, 50 \%)$.

${ }^{1}$ H-NMR $\left(300 \mathrm{MHz}, \mathrm{CDCl}_{3}\right): \delta$ 7.33-7.26 (m, 5H), 5.76-5.73 (m, 1H), $4.45(\mathrm{~s}, 2 \mathrm{H})$, 4.05-4.03 (dd, $J=4.5 \mathrm{~Hz}, 1.2 \mathrm{~Hz}, 1 \mathrm{H}), 3.59-3.50(\mathrm{~m}, 2 \mathrm{H}), 2.54-2.53(\mathrm{~d}, J=4.5 \mathrm{~Hz}, 1 \mathrm{H}), 2.52-2.51$ (d, $J=1.2 \mathrm{~Hz}, 1 \mathrm{H}$ ), 2.41-2.20 (comp. m, 6H), 1.94-1.86 (ddd, $J=10.6 \mathrm{~Hz}, 3.8 \mathrm{~Hz}, 2.4 \mathrm{~Hz}, 1 \mathrm{H}$ ), $1.28(\mathrm{~s}, 3 \mathrm{H}), 1.06(\mathrm{~s}, 3 \mathrm{H}) ;{ }^{13} \mathrm{C}-\mathrm{NMR}\left(75 \mathrm{MHz}, \mathrm{CDCl}_{3}\right): \delta 174.6,137.7,133.2,128.0,127.4,127.3$, 124.0, 97.8, 84.4, 79.1,72.6, 68.4, 53.2, 36.5, 35.1, 34.1, 29.1, 23.4, 22.0; HRMS (EI): $\mathrm{m} / \mathrm{z}$ found: 342.1826 [calc'd for $\mathrm{C}_{21} \mathrm{H}_{26} \mathrm{O}_{4}: 342.1831$ ].

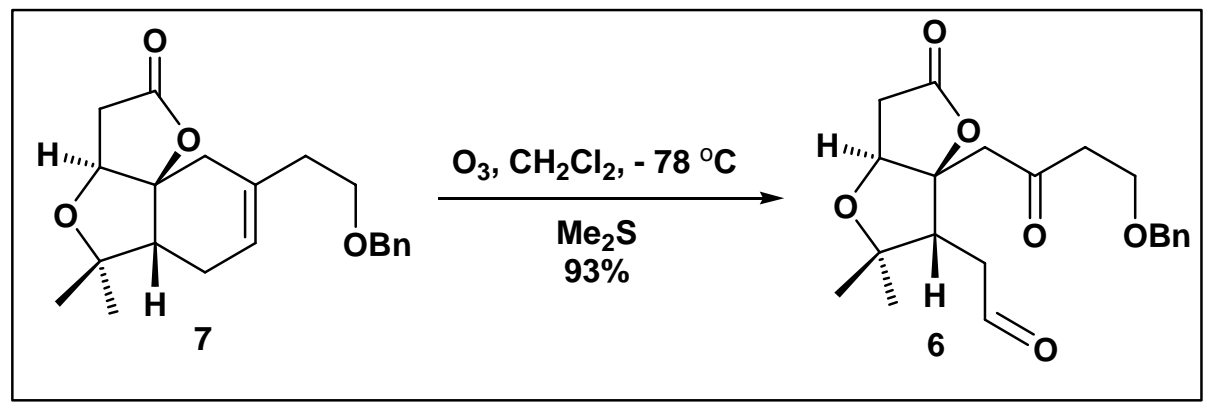

Compound 6: Ozone was passed through a solution of compound $7(1.31 \mathrm{~g}, 3.84 \mathrm{mmol})$ in dried $\mathrm{CH}_{2} \mathrm{Cl}_{2}(20 \mathrm{~mL})$ at $-78{ }^{\circ} \mathrm{C}$ until a blue color persisted. The mixture was then flushed with $\mathrm{N}_{2}$ to remove excess ozone, and then methyl sulfide $(1.1 \mathrm{ml}, 15.4 \mathrm{mmol})$ was added. The mixture was stirred overnight, during which time the temperature was allowed to warm to room temperature. The solvent was removed under vacuum and the residue was purified by $\mathrm{SiO}_{2}$ flash chromatography (petroleum ether/ethyl acetate $=1 / 1)$ to provide product 6 as a colorless oil $(1.34$ g, $93 \%)$.

${ }^{1}$ H-NMR $\left(300 \mathrm{MHz}, \mathrm{CDCl}_{3}\right): \delta 9.72-9.71(\mathrm{t}, J=1.8 \mathrm{~Hz}, 1 \mathrm{H}), 7.37-7.27(\mathrm{~m}, 5 \mathrm{H})$, 4.52-4.48 (dd, $\left.J_{1}=4.8 \mathrm{~Hz}, J_{2}=2.7 \mathrm{~Hz}, 1 \mathrm{H}\right), 4.48(\mathrm{~s}, 2 \mathrm{H}), 3.74-3.66(\mathrm{~m}, 2 \mathrm{H}), 3.34-3.26\left(\mathrm{dd}, J_{1}=\right.$ $\left.18.3 \mathrm{~Hz}, J_{2}=7.2,1 \mathrm{H}\right), 3.12-3.06(\mathrm{~d}, J=18.3 \mathrm{~Hz}, 1 \mathrm{H}), 2.80-2.74(\mathrm{~d}, J=18.3 \mathrm{~Hz}, 1 \mathrm{H}), 2.77-2.03$ (m, 6H), 1.27 (s, 3H), 1.02 (s, 3H); ${ }^{13}$ C-NMR $\left(75 \mathrm{MHz}, \mathrm{CDCl}_{3}\right): \delta$ 205.4, 199.7, 175.8, 137.5, 129.3, 128.2, 127.6, 92.3, 81.8, 78.6, 73.0,65.0, 53.7, 46.8,43.3, 40.4, 38.2, 27.4, 20.5; LRMS (EI): $\mathrm{m} / \mathrm{z} 374$. 


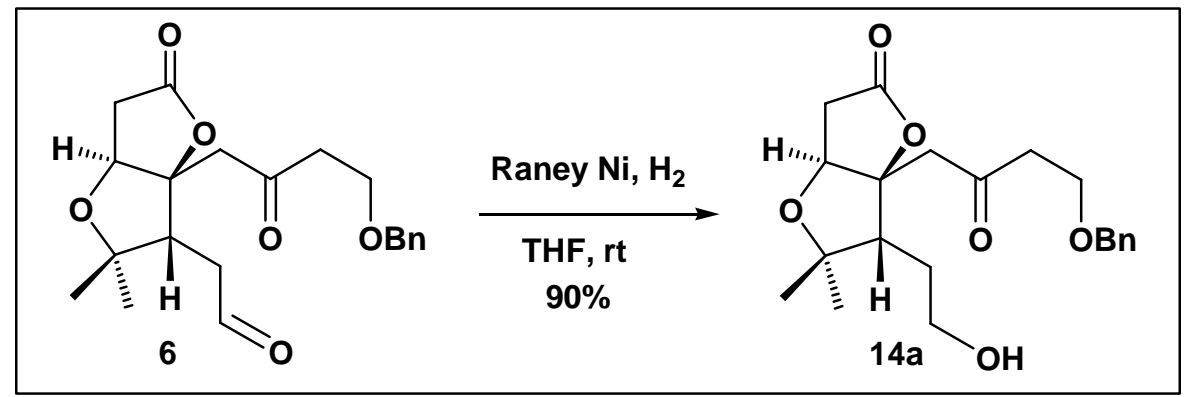

Compound 14a: To the solution of keto-aldehyde (0.69 g, $1.84 \mathrm{mmol})$ in THF (30 mL) at room temperature was added Raney $\mathrm{Ni}^{*}$ (W-6, $70 \mathrm{mg}$ ) in water. After degassing with $\mathrm{H}_{2}$, the mixture was stirred under $\mathrm{H}_{2}$ for $1 \mathrm{~h}$. The solution was filtered through a pad of silica gel and the filtrate was concentrated under vacuum, and the residue was purified by $\mathrm{SiO}_{2}$ flash chromatograph (petroleum ether/ ethyl acetate $=1 / 2)$ to give product 14a $(0.63 \mathrm{~g}, 90 \%)$.

${ }^{1}$ H-NMR (300 MHz, $\mathrm{CDCl}_{3}$ ): $\delta$ 7.36-7.26 (m, 5H), 4.50-4.49 (dd, overlap, 1H), 4.47 (s, $2 \mathrm{H}), 3.75-3.65(\mathrm{~m}, 4 \mathrm{H}), 3.44-3.38(\mathrm{~d}, J=18.6 \mathrm{~Hz}, 1 \mathrm{H}), 3.37-3.28$ (dd, $J=18.6 \mathrm{~Hz}, 7.5 \mathrm{~Hz}, 1 \mathrm{H})$, 2.84-2.78 (d, $J=18.6 \mathrm{~Hz}, 1 \mathrm{H}), 2.65-2.53(\mathrm{~m}, 3 \mathrm{H}), 2.04-1.99(\mathrm{~m}, 1 \mathrm{H}), 1.59-1.46(\mathrm{~m}, 2 \mathrm{H}), 1.25(\mathrm{~s}$, 3H), $0.98(\mathrm{~s}, 3 \mathrm{H}) ;{ }^{13} \mathrm{C}-\mathrm{NMR}\left(75 \mathrm{MHz}, \mathrm{CDCl}_{3}\right): \delta 206.0,176.5,137.5,129.4,128.2,127.6,92.9$, 82.3, 78.6, 73.1, 65.2, 60.8, 56.9, 46.9,43.3, 38.5, 28.1, 27.6, 20.2; LRMS (EI): m/z 376 .

[* See: Org. Syn. Coll. Vol. 3, 176P (1955).]

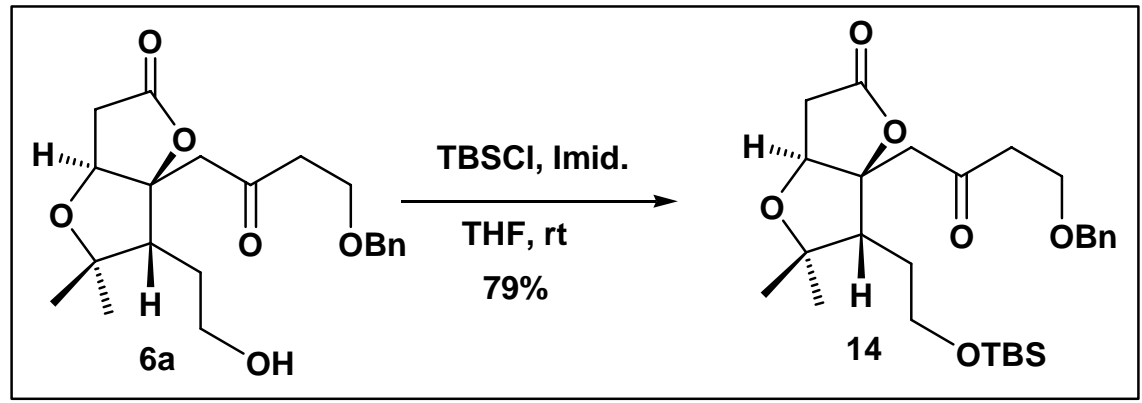

Compound 14: A solution of keto-alcohol (0.63 g, $1.67 \mathrm{mmol})$ in anhydrous THF (20 mL) was treated with $\operatorname{TBSCl}(0.30 \mathrm{~g}, 1.99 \mathrm{mmol})$ and imidazole $(0.16 \mathrm{~g}, 2.32 \mathrm{mmol})$ at room temperature. After stirring for $12 \mathrm{~h}$, the solution was quenched with water, and extracted with ether $(3 \times 20 \mathrm{~mL})$. The combined organic layers were washed with brine $(2 \times 5 \mathrm{~mL})$, and dried over $\mathrm{Na}_{2} \mathrm{SO}_{4}$. The solvent was removed under vacuum and the residue was purified by $\mathrm{SiO}_{2}$ flash chromatography (petroleum ether/ethyl acetate $=2 / 1)$ to give product 14 as a colorless oil $(0.65 \mathrm{~g}$, $79 \%)$.

${ }^{1}$ H-NMR (300MHz, $\mathrm{CDCl}_{3}$ ): $\delta$ 7.34-7.26 (m, 5H), 4.51-4.50 (dd, overlap, 1H), $4.50(\mathrm{~s}$, 2H), 3.75-3.61 (m, 4H), 3.37-3.34 (d, $J=10.8 \mathrm{~Hz}, 1 \mathrm{H}), 3.28-3.25$ (d, $J=10.5 \mathrm{~Hz}, 1 \mathrm{H}), 2.82-2.51$ $(\mathrm{m}, 4 \mathrm{H}), \quad 2.05-1.98(\mathrm{dd}, J=14.1 \mathrm{~Hz}, 6.6 \mathrm{~Hz}, 1 \mathrm{H}), 1.60-1.40(\mathrm{~m}, 2 \mathrm{H}), 1.28(\mathrm{~s}, 3 \mathrm{H}), 0.94(\mathrm{~s}, 3 \mathrm{H})$, 0.89 (s, 9H), 0.07 (s, 3H), 0.06 (s, 3H); ${ }^{13} \mathrm{C}-\mathbf{N M R}\left(75 \mathrm{MHz}, \mathrm{CDCl}_{3}\right): \delta 205.6,176.1,137.7,128.3$, 127.7, 127.6, 92.8, 82.4, 78.7, 73.3, 65.2, 61.5, 56.7, 47.1, 43.7, 38.5, 29.1, 27.8, 25.8, 20.3, 18.2, -5.3; LRMS (EI): $m / z 490$. 


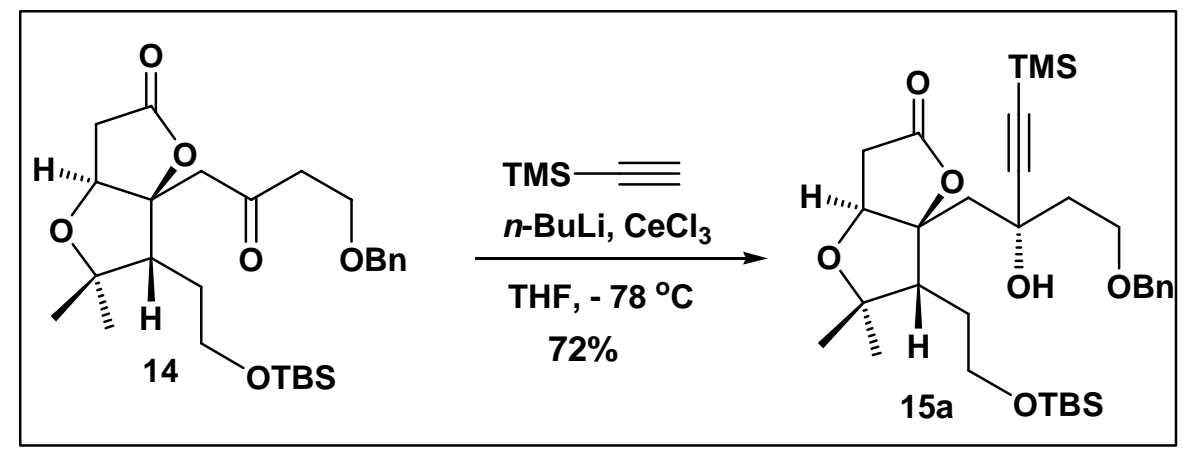

Compound 15a: To the solution of trimethylsilyl acetylene $(0.58 \mathrm{ml}, 4.07 \mathrm{mmol})$ in anhydrous THF $(10 \mathrm{~mL})$ at $-78^{\circ} \mathrm{C}$ was added $n$-BuLi $(2.5 \mathrm{M}$ in hexanes, $1.36 \mathrm{ml}, 3.34 \mathrm{mmol})$ in dropwise, and the mixture was stirred at the same temperature for $1 \mathrm{~h}$. After addition of anhydrous cerium chloride $(0.836 \mathrm{~g}, 3.39 \mathrm{mmol})$ at $-78^{\circ} \mathrm{C}$, the mixture was vigorously stirred for $2 \mathrm{~h}$ at the same temperature. After addition of this organocerium reagent in THF to the solution of ketone 14 $(0.83 \mathrm{~g}, 1.70 \mathrm{mmol})$ in $\mathrm{THF}(20 \mathrm{~mL})$ at $-78^{\circ} \mathrm{C}$ by cannulation over ca. $15 \mathrm{~min}$. the mixture was continually stirred at $-78^{\circ} \mathrm{C}$ for additional $3 \mathrm{~h}$. The reaction was quenched by addition of saturated Roche's salt solution $(5 \mathrm{~mL})$ and extracted with EtOAc $(3 \times 30 \mathrm{~mL})$. The combined organic layers were washed with brine $(2 \times 5 \mathrm{~mL})$, and dried over $\mathrm{Na}_{2} \mathrm{SO}_{4}$. The solvent was removed under vacuum and the residue was purified by $\mathrm{SiO}_{2}$ flash chromatography (petroleum ether/ethyl acetate $=4 / 1)$ to give product $15 \mathbf{a}$ as a colorless oil $(0.76 \mathrm{~g}, 72 \%)$.

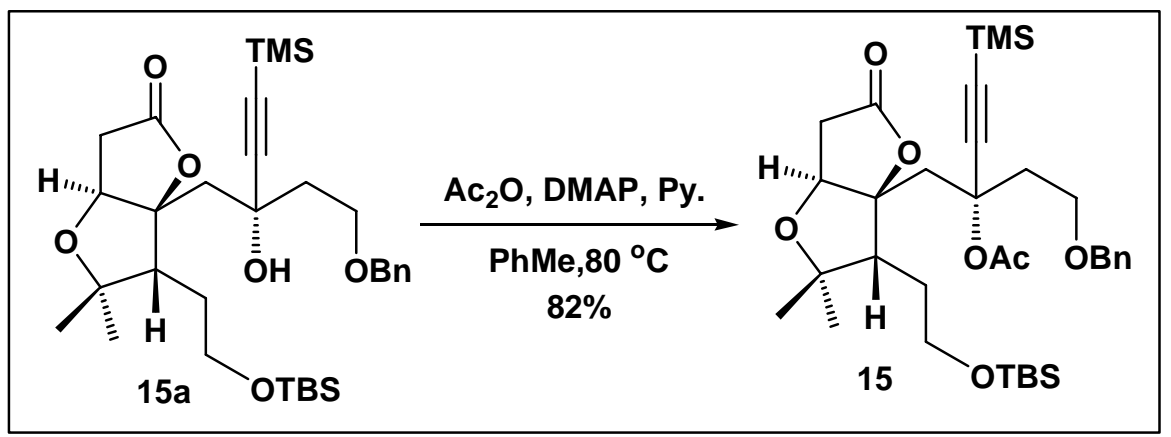

Compound 15: To the solution of acetylene alcohol $(0.76 \mathrm{~g}, 1.29 \mathrm{mmol})$ in toluene $(20 \mathrm{~mL})$ was sequentially added $\mathrm{Ac}_{2} \mathrm{O}(0.73 \mathrm{~mL}, 7.77 \mathrm{mmol})$, DMAP $(0.063 \mathrm{~g}, 0.52 \mathrm{mmol})$ and pyridine $(0.63 \mathrm{~mL}, 7.77 \mathrm{mmol})$, and the mixture was heated at $80^{\circ} \mathrm{C}$ for $48 \mathrm{~h}$. After cooling the mixture to room temperature, and water $(10 \mathrm{~mL})$ was added and the mixture was extracted with EtOAc $(3 \mathrm{x}$ $20 \mathrm{~mL})$. The combined organic layers were washed with brine $(2 \times 5 \mathrm{~mL})$, and dried over $\mathrm{Na}_{2} \mathrm{SO}_{4}$. The solvent was removed under vacuum and the residue was purified by $\mathrm{SiO}_{2}$ flash chromatography (petroleum ether/ethyl acetate $=10 / 1)$ to give product $\mathbf{1 5}$ as a colorless oil $(0.67 \mathrm{~g}$, $82 \%)$.

${ }^{1}$ H-NMR $\left(300 \mathrm{MHz}, \mathrm{CDCl}_{3}\right): \delta$ 7.39-7.28 (m, 5H), 5.40-5.38 (dd, J=6.9 Hz, 0.9 Hz, $\left.1 \mathrm{H}\right)$, 4.55-4.51 (d, $J=12 \mathrm{~Hz}, 1 \mathrm{H}), 4.48-4.44(\mathrm{~d}, J=12 \mathrm{~Hz}, 1 \mathrm{H}), 3.79-3.58(\mathrm{~m}, 4 \mathrm{H}), 3.21-3.15(\mathrm{~d}, J=$ $15.6 \mathrm{~Hz}, 1 \mathrm{H}), 3.20-3.11(\mathrm{dd}, J=18.6 \mathrm{~Hz}, 6.9 \mathrm{~Hz}, 1 \mathrm{H}), 2.68-2.62(\mathrm{dd}, J=18.6 \mathrm{~Hz}, 0.9 \mathrm{~Hz} 1 \mathrm{H})$, 2.69-2.61 (m, 1H), 2.45-2.34 (m, 1H), 2.17-2.12 (d, $J=15.6 \mathrm{~Hz}, 1 \mathrm{H}), 2.13-2.09$ (dd, $J=10.2 \mathrm{~Hz}$, $4.2 \mathrm{~Hz}, 1 \mathrm{H}), 2.00(\mathrm{~s}, 3 \mathrm{H}), 1.57-1.30(\mathrm{~m}, 2 \mathrm{H}), 1.30(\mathrm{~s}, 3 \mathrm{H}), 1.01(\mathrm{~s}, 3 \mathrm{H}), 0.93(\mathrm{~s}, 9 \mathrm{H}), 0.20(\mathrm{~s}, 9 \mathrm{H})$, $0.10(\mathrm{~s}, 3 \mathrm{H}), 0.09(\mathrm{~s}, 3 \mathrm{H}) ;{ }^{13} \mathrm{C}-\mathrm{NMR}\left(75 \mathrm{MHz}, \mathrm{CDCl}_{3}\right): \delta 175.7,169.4,137.9,128.2,127.4,127.4$, 103.6, 95.5, 92.9, 82.2, 76.5, 76.0, 72.9, 66.2, 61.0, 57.7, 41.2, 39.7, 37.3, 28.7, 27.4, 25.8, 21.8, 


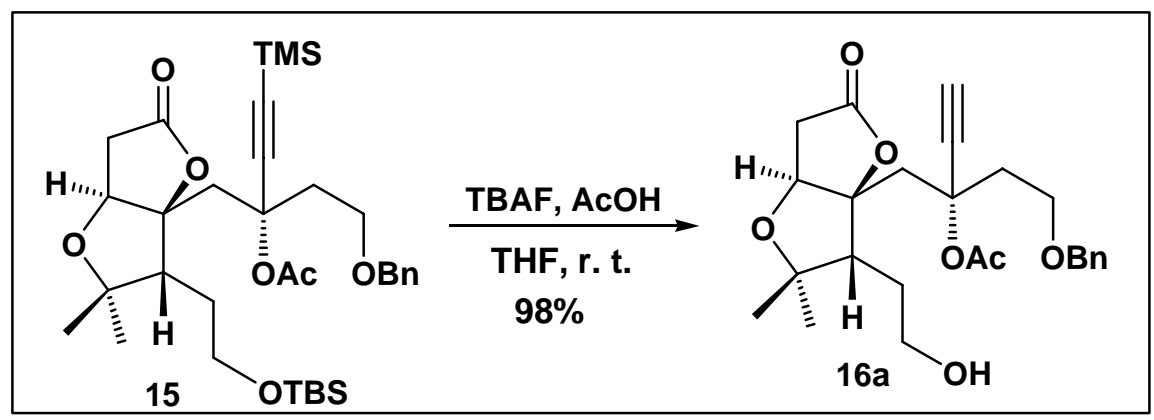

Compound 16a: To a solution of compound 15 (0.296 g, $0.47 \mathrm{mmol})$ in THF (20 mL) was sequentially added $\mathrm{AcOH}(0.28 \mathrm{~mL}, 4.70 \mathrm{mmol})$ and $\mathrm{TBAF} \cdot 3 \mathrm{H}_{2} \mathrm{O}(0.445 \mathrm{~g}, 0.47 \mathrm{mmol})$ at room temperature. After stirring at the same temperature for $12 \mathrm{~h}$, the reaction was quenched with water $(5 \mathrm{~mL})$, and the mixture was extracted with ether $(3 \times 15 \mathrm{~mL})$. The combined organic layers were washed with brine $(2 \times 5 \mathrm{~mL})$, and dried over $\mathrm{Na}_{2} \mathrm{SO}_{4}$. The solvent was removed under vacuum and the residue was purified by $\mathrm{SiO}_{2}$ flash chromatography (petroleum ether/ethyl acetate $=1 / 1)$ to give product $16 \mathbf{a}$ as a colorless oil $(0.204 \mathrm{~g}, 98 \%)$.

${ }^{1}$ H-NMR $\left(300 \mathrm{MHz}, \mathrm{CDCl}_{3}\right): \delta 7.35-7.28(\mathrm{~m}, 5 \mathrm{H}), 5.32-5.29(\mathrm{dd}, J=6.9 \mathrm{~Hz}, 0.9 \mathrm{~Hz}, 1 \mathrm{H})$, 4.51-4.47 (d, $J=11.7 \mathrm{~Hz}, 1 \mathrm{H}), 4.46-4.42(\mathrm{~d}, J=11.7 \mathrm{~Hz}, 1 \mathrm{H}), 3.76-3.56(\mathrm{~m}, 4 \mathrm{H}), 3.17-3.12(\mathrm{~d}, J$ $=15.6 \mathrm{~Hz}, 1 \mathrm{H}), 3.11-3.02(\mathrm{dd}, J=18.6 \mathrm{~Hz}, 6.9 \mathrm{~Hz}, 1 \mathrm{H}), 2.78(\mathrm{~s}, 1 \mathrm{H}), 2.66-2.60(\mathrm{dd}, J=18.6 \mathrm{~Hz}$, $0.9 \mathrm{~Hz}, 1 \mathrm{H}), 2.66-2.58(\mathrm{~m}, 1 \mathrm{H}), 2.45-2.38(\mathrm{~m}, 2 \mathrm{H}), 2.20-2.15(\mathrm{~d}, J=15.6 \mathrm{~Hz}, 1 \mathrm{H}), 2.09-2.04(\mathrm{dd}$, $J=10.5 \mathrm{~Hz}, 4.2 \mathrm{~Hz}, 1 \mathrm{H}), 1.98$ (s, 3H), 1.60-1.35 (m, 2H), 1.28 (s, 3H), 1.00 (s, 3H); ${ }^{13}$ C-NMR $\left(75 \mathrm{MHz}, \mathrm{CDCl}_{3}\right): \delta 175.7,169.4,137.7,128.2,127.6,127.5,95.2,82.3,82.1,76.5,75.9,75.8$, 72.9, 66.0, 60.5, 58.1, 41.3, 39.5, 37.4,28.1, 27.5, 21.7, 20.1; LRMS (EI): m/z 444.

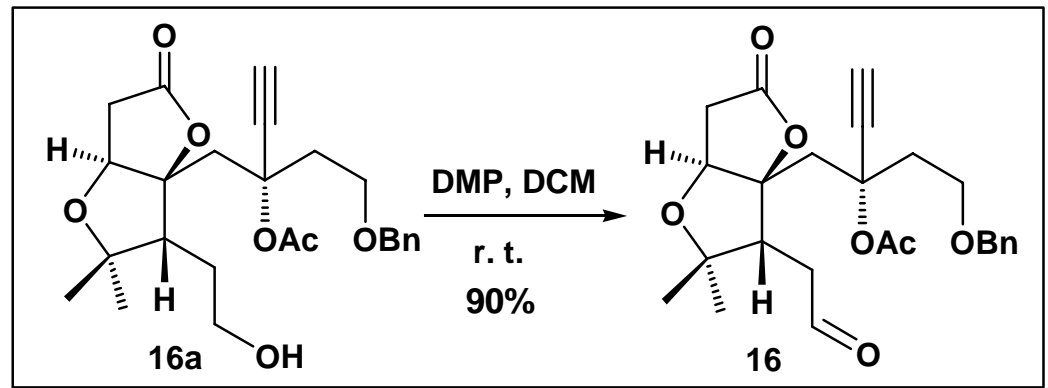

Compound 16: A solution of above alcohol $(0.204 \mathrm{~g}, 0.459 \mathrm{mmol})$ in $\mathrm{CH}_{2} \mathrm{Cl}_{2}(5 \mathrm{~mL})$ at room temperature was added Dess-Martin periodinane $(0.234 \mathrm{~g}, 0.551 \mathrm{mmol})$, and the mixture was stirred at the same temperature for $3.5 \mathrm{~h}$. The reaction was quenched by addition of water ( 5 $\mathrm{mL})$, and the mixture was extracted with EtOAc $(3 \times 10 \mathrm{~mL})$. The combined extract was washed with brine $(2 \times 3 \mathrm{~mL})$, and dried over $\mathrm{Na}_{2} \mathrm{SO}_{4}$. The solvent was removed under vacuum the residue was purified by $\mathrm{SiO}_{2}$ flash chromatography (petroleum ether/ethyl acetate $=1 / 1$ ) to afford the product $16(0.183 \mathrm{~g}, 90 \%)$ as a colorless oil.

${ }^{1} \mathrm{H}-\mathrm{NMR}\left(300 \mathrm{MHz}, \mathrm{CDCl}_{3}\right): \delta 9.63-9.62(\mathrm{t}, J=4.8 \mathrm{~Hz}, 1 \mathrm{H}), 7.38-7.27(\mathrm{~m}, 5 \mathrm{H})$, 5.23-5.21 (d, $J=5.9 \mathrm{~Hz}, 1 \mathrm{H}), 4.51-4.47(\mathrm{~d}, J=11.4 \mathrm{~Hz}, 1 \mathrm{H}), 4.45-4.42(\mathrm{~d}, J=11.4 \mathrm{~Hz}, 1 \mathrm{H})$, 3.77-3.72 (m, 1H), 3.68-3.62 (m, 1H), 3.06-2.98 (dd, $J=6.9 \mathrm{~Hz}, 2.4 \mathrm{~Hz}, 1 \mathrm{H}), 2.87-2.82(\mathrm{~d}, J=$ $15.6 \mathrm{~Hz}, 1 \mathrm{H}), 2.76(\mathrm{~s}, 1 \mathrm{H}), 2.73-2.62(\mathrm{~m}, 2 \mathrm{H}), 2.59-2.36(\mathrm{~m}, 5 \mathrm{H}), 2.22-2.19$ (ddd, $J=17.1 \mathrm{~Hz}, 6.9$ 
Hz, $2.4 \mathrm{~Hz}, 1 \mathrm{H}), 2.17-2.11$ (d, $J=15.6 \mathrm{~Hz}, 1 \mathrm{H}), 1.98$ (s, 3H), 1.29 (s, 3H), 1.05 (s, 3H); ${ }^{13}$ C-NMR $\left(75 \mathrm{MHz}, \mathrm{CDCl}_{3}\right): \delta 199.4,175.2,169.1,137.7,128.2,127.6,127.5,94.9,82.1,81.8,76.6,76.4$, 75.3, 72.9, 65.9, 54.9, 41.9, 40.4, 39.5, 37.2, 27.5, 21.6, 20.8; LRMS (EI): $\mathrm{m} / \mathrm{z} 442$.

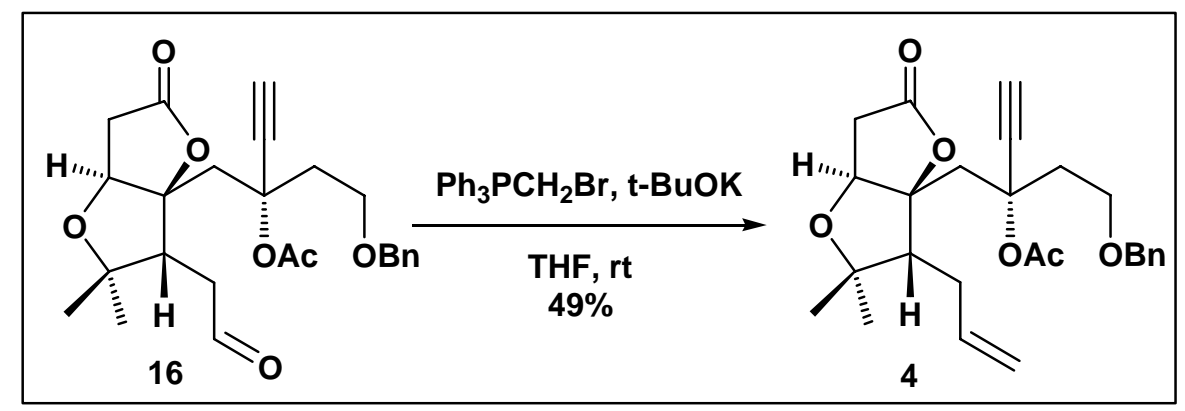

Compound 4: To a solution of methyltriphenylphosphonium bromide $(0.239 \mathrm{~g}, 0.67$ mmol) in anhydrous THF $(5 \mathrm{~mL})$ was added $t$-BuOK $(0.075 \mathrm{~g}, 0.67 \mathrm{mmol})$ at room temperature, and the mixture was stirred at the same temperature for $1 \mathrm{~h}$. After addition of the Wittig reagent prepared above to the solution of aldehyde $16(0.148 \mathrm{~g}, 0.355 \mathrm{mmol})$ in THF $(10 \mathrm{~mL})$ by cannulation, the mixture was stirred at room temperature for $1 \mathrm{~h}$. The reaction was quenched with $\mathrm{NH}_{4} \mathrm{Cl}$ solution $(5 \mathrm{~mL})$, and the mixture was extracted with EtOAc $(3 \times 10 \mathrm{~mL})$. The combined extract was washed with brine $(2 \times 3 \mathrm{~mL})$, and dried over $\mathrm{Na}_{2} \mathrm{SO}_{4}$. The solvent was removed under vacuum and the residue was purified by $\mathrm{SiO}_{2}$ flash chromatography (petroleum ether/ethyl acetate $=4 / 1)$ to give product $4(0.078 \mathrm{~g}, 49 \%)$ as a colorless oil.

${ }^{1}$ H-NMR $\left(300 \mathrm{MHz}, \mathrm{CDCl}_{3}\right): \delta$ 743-7.29 (m, 5H), 5.83-5.63 (m, 1H), 5.28-5.24 (dd, $J=$ $3.6 \mathrm{~Hz}, 0.6 \mathrm{~Hz}, 1 \mathrm{H}), 5.11-5.07$ (dd, $J=9.3 \mathrm{~Hz}, 1.2 \mathrm{~Hz}, 1 \mathrm{H}), 5.0-5.02(\mathrm{~m}, 1 \mathrm{H}), 4.51-4.47$ (d, $J=$ $14.1 \mathrm{~Hz}, 1 \mathrm{H}), 4.45-4.11(\mathrm{~d}, J=14.1 \mathrm{~Hz}, 1 \mathrm{H}), 3.80-3.57(\mathrm{~m}, 2 \mathrm{H}), 3.13-3.05(\mathrm{~d}, J=23.4 \mathrm{~Hz}, 1 \mathrm{H})$, 3.10-2.97 (dd, $J=18 \mathrm{~Hz}, 10.2 \mathrm{~Hz}, 1 \mathrm{H}$ ), 2.73 (s, $1 \mathrm{H}$ ), 2.68-2.32 (m, 3H), 2.16-2.08 (d, $J=23.4 \mathrm{~Hz}$, 1H), 2.20-2.05 (m, 3H), 2.05 (s, 3H), $1.28(\mathrm{~s}, 3 \mathrm{H}), 1.04(\mathrm{~s}, 3 \mathrm{H}) ;{ }^{13}$ C-NMR $\left(75 \mathrm{MHz}, \mathrm{CDCl}_{3}\right): \delta$ $175.8,169.3,137.9,135.3,128.3,127.6,127.6,116.8,95.7,82.4,82.3,75.8,75.7,73.0,66.0,60.2$, 41.4, 39.7, 37.5, 30.1, 29.6, 28.0, 21.8,20.2; LRMS (EI): $\mathrm{m} / \mathrm{z} 440$.

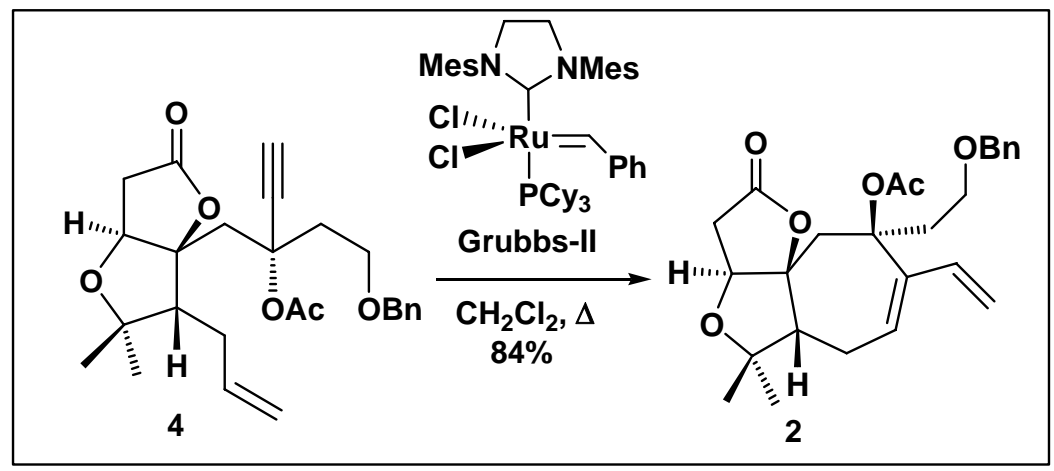

Compound 2: To a solution of eneyne $4(0.019 \mathrm{mg}, 0.043 \mathrm{mmol})$ in anhydrous $\mathrm{CH}_{2} \mathrm{Cl}_{2}$ (30 mL) was added Grubss-II catalyst $(0.011 \mathrm{~g}, 0.013 \mathrm{mmol})$ in $\mathrm{CH}_{2} \mathrm{Cl}_{2}(1 \mathrm{~mL})$ at room temperature under $\mathrm{N}_{2}$ by cannunlation, and the mixture was heated at $45^{\circ} \mathrm{C}$ for $12 \mathrm{~h}$. The reaction mixture was then filtered through a pad of silica gel and washed with $\mathrm{CH}_{2} \mathrm{Cl}_{2}(30 \mathrm{~mL})$. The filtrate was removed under vacuum and the residue was purified by $\mathrm{SiO}_{2}$ flash chromatograph (petroleum ether/ethyl acetate $=3 / 1)$ to give product $2(0.016 \mathrm{~g}, 84 \%)$. 
${ }^{1}$ H-NMR $\left(400 \mathrm{~Hz}, \mathrm{CDCl}_{3}\right): \delta 7.35-7.28(\mathrm{~m}, 5 \mathrm{H}), 6.24-6.17(\mathrm{dd}, J=17.2 \mathrm{~Hz}, 10.8 \mathrm{~Hz}, 1 \mathrm{H})$, 6.07-6.03 (dd, $J=9.6 \mathrm{~Hz}, 4.0 \mathrm{~Hz}, 1 \mathrm{H}), 5.31-5.26(\mathrm{dd}, J=17.2 \mathrm{~Hz}, 1.6 \mathrm{~Hz}, 1 \mathrm{H}), 5.00-4.97$ (dd, $J=$ $10.8 \mathrm{~Hz}, 1.6 \mathrm{~Hz}, 1 \mathrm{H}), 4.49-4.46(\mathrm{~d}, J=11.6 \mathrm{~Hz}, 1 \mathrm{H}), 4.47-4.18(\mathrm{~d}, J=11.6 \mathrm{~Hz}, 1 \mathrm{H}), 4.15-4.14$ (d, $J=4.8 \mathrm{~Hz}, 1 \mathrm{H}), 3.73-3.68(\mathrm{~m}, 1 \mathrm{H}), 3.62-3.59(\mathrm{~m}, 1 \mathrm{H}), 3.30-3.26(\mathrm{dd}, J=14.4 \mathrm{~Hz}, 0.8 \mathrm{~Hz}, 1 \mathrm{H})$, 2.57-2.52 (m, 1H), 2.46-2.39 (m, 3H), 2.31-2.21 (m, 3H), 2.08-2.04 (m, 1H), $1.98(\mathrm{~s}, 3 \mathrm{H}), 1.30(\mathrm{~s}$, 3H), $1.12(\mathrm{~s}, 3 \mathrm{H}) ;{ }^{13} \mathrm{C}-\mathrm{NMR}\left(100 \mathrm{MHz}, \mathrm{CDCl}_{3}\right): \delta 174.8,169.7,140.7,138.1,136.6,128.3,128.2$, 128.1, 127.6, 115.3, 96.2, 84.5, 84.2, 81.1, 73.3, 66.0, 56.5, 38.5, 36.0, 35.8, 29.1, 25.3, 22.5, 22.0; HRMS (EI): $\mathrm{m} / \mathrm{z}$ found: 440.2195, [calc'd for $\mathrm{C}_{26} \mathrm{H}_{32} \mathrm{O}_{6}: 440.2198$ ].

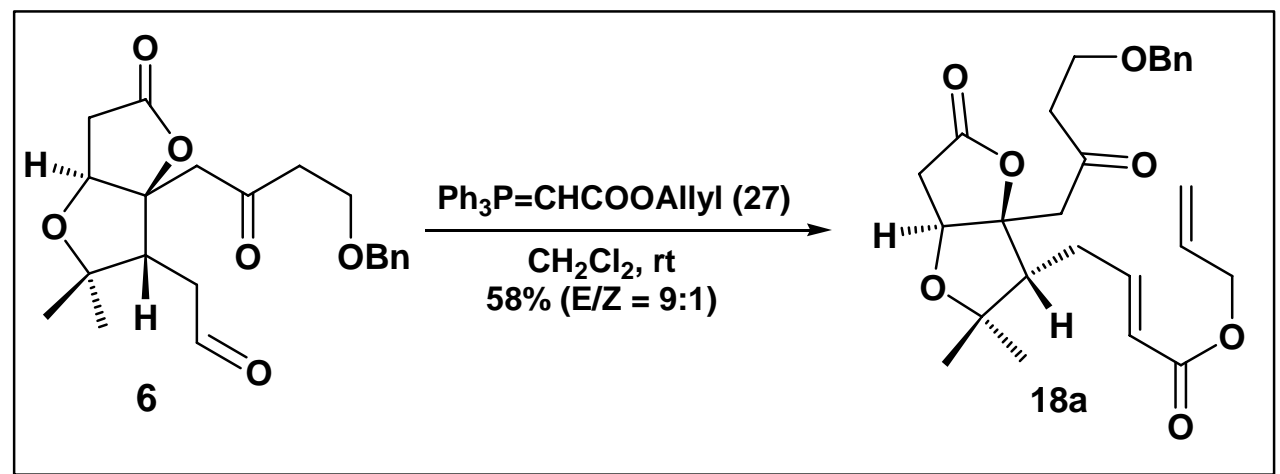

Compound 18a: To a solution of keto-aldehyde $6(0.422 \mathrm{~g}, 1.128 \mathrm{mmol})$ in $\mathrm{CH}_{2} \mathrm{Cl}_{2}(10$ $\mathrm{mL}$ ) was added the Wittig reagent $27(0.812 \mathrm{~g}, 2.257 \mathrm{mmol})$ at room temperature, and the mixture was stirred at the same temperature for $24 \mathrm{~h}$. The reaction was worked up by removing the solvent under vacuum and the residue was purified by $\mathrm{SiO}_{2}$ flash chromatography (petroleum ether/ethyl acetate $=2 / 1)$ to give the desired product 18a $(0.265 \mathrm{~g}, 52 \%)$ as a colorless and its $\mathrm{Z}$ isomer $(6 \%)$.

${ }^{1}$ H-NMR $\left(300 \mathrm{MHz}, \mathrm{CDCl}_{3}\right): \delta$ 7.37-7.25 (m, 5H), 7.00-6.90 (m, 1H), 6.03-5.97 (d, $J=$ 15.6 Hz, 1H), 6.02-5.88 (m, 1H), 5.36-5.22 (m, 2H), 4.67-4.57 (m, 2H), 4.51-4.49 (dd, overlap, $1 \mathrm{H}), 4.47$ (s, 2H), 3.76-3.62 (m, 2H), 3.36-3.27 (dd, $J=18.6 \mathrm{~Hz}, 7.2 \mathrm{~Hz}, 1 \mathrm{H}), 3.23-3.17$ (d, $J=18$ $\mathrm{Hz}, 1 \mathrm{H}), 2.82-2.75(\mathrm{~d}, J=18 \mathrm{~Hz}, 1 \mathrm{H}), 2.77-2.67(\mathrm{~m}, 1 \mathrm{H}), 2.61-2.52(\mathrm{~m}, 2 \mathrm{H}), 2.34-2.27(\mathrm{~m}, 1 \mathrm{H})$, 2.24-2.12 (m, 2H), 1.27 (s, 3H), 0.96 (s, 3H); ${ }^{13}$ C-NMR (75MHz, $\left.\mathrm{CDCl}_{3}\right)$ : $\delta$ 205.5, 175.9, 165.3, 145.6, 137.5, 131.9, 128.3, 127.6, 127.6, 122.9, 118.2, 92.5, 82.1, 78.6, 73.2, 65.1, 65.0, 58.0, 46.5, 43.5, 38.2, 28.7, 27.9, 20.2; LRMS (EI): m/z 456.

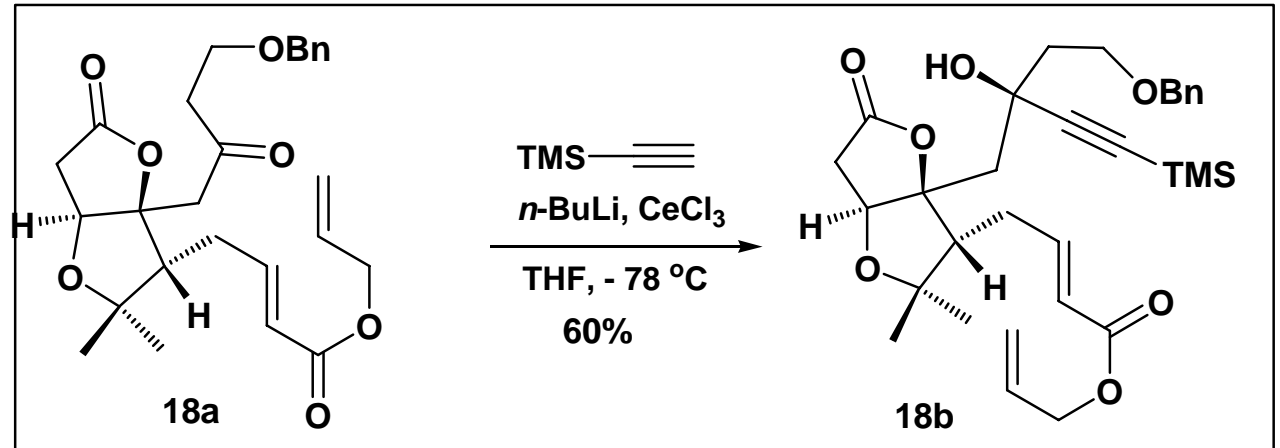

Compound 18b: To the solution of trimethylsilyl acetylene $(0.37 \mathrm{~mL}, 2.58 \mathrm{mmol})$ in anhydrous THF $(10 \mathrm{~mL})$ was added $n$-BuLi $(1.6 \mathrm{M}$ in hexanes, $1.35 \mathrm{~mL}, 2.15 \mathrm{~mol})$ at $-78{ }^{\circ} \mathrm{C}$ in dropwise, and the mixture was stirred at the same temperature for $1 \mathrm{~h}$. After addition of anhydrous cerium chloride $(0.53 \mathrm{~g}, 2.15 \mathrm{mmol})$, the mixture was vigorously stirred at the same temperature 
for $2 \mathrm{~h}$. To this solution was added ketone 18a $(0.50 \mathrm{~g}, 1.08 \mathrm{mmol})$ in THF $(20 \mathrm{~mL})$ at $-78^{\circ} \mathrm{C}$ by cannulaiton during $15 \mathrm{~min}$. and the reaction mixture was continually stirred at the same temperature for $3 \mathrm{~h}$. The reaction was quenched by addition of a saturated Rochelle's salt solution $(3 \mathrm{~mL})$, and the mixture was extracted with EtOAc $(3 \times 30 \mathrm{~mL})$. The combined organic layers were washed with brine $(2 \times \times 5 \mathrm{~mL})$, and dried over $\mathrm{Na}_{2} \mathrm{SO}_{4}$. The solvent was removed under vacuum and the residue was purified by $\mathrm{SiO}_{2}$ flash chromatography (petroleum ether/ethyl acetate $=2 / 1)$ to give product $\mathbf{1 8 b}$ as a colorless oil $(0.352 \mathrm{~g}, 60 \%)$.

${ }^{1}$ H-NMR (300MHz, $\left.\mathrm{CDCl}_{3}\right): \delta$ 7.38-7.26 (m, 5H), 7.02-6.93 (dt, $\left.J=15.6 \mathrm{~Hz}, 5.4 \mathrm{~Hz}, 1 \mathrm{H}\right)$, 6.01-5.96 (d, $J=15.6 \mathrm{~Hz}, 1 \mathrm{H}), 6.00-5.88(\mathrm{~m}, 1 \mathrm{H}), 5.37-5.35(\mathrm{~m}, 1 \mathrm{H}), 5.35-5.22(\mathrm{~m}, 2 \mathrm{H})$, 4.69-4.58 (m, 2H), $4.50(\mathrm{~s}, 2 \mathrm{H}), 4.12-4.01(\mathrm{~m}, 1 \mathrm{H}), 3.73-3.67(\mathrm{~m}, 1 \mathrm{H}), 3.25-3.16(\mathrm{dd}, J=18.6 \mathrm{~Hz}$, $7.2 \mathrm{~Hz}, 1 \mathrm{H}), 2.56-2.40(\mathrm{~d}, J=18.6 \mathrm{~Hz}, 1 \mathrm{H}), 2.32-2.25(\mathrm{~m}, 1 \mathrm{H}), 2.32-2.08(\mathrm{~m}, 5 \mathrm{H}), 1.72-1.67(\mathrm{~m}$, $1 \mathrm{H}), 1.28(\mathrm{~s}, 3 \mathrm{H}), 1.10(\mathrm{~s}, 3 \mathrm{H}), 0.16(\mathrm{~s}, 9 \mathrm{H}) ;{ }^{13} \mathrm{C}-\mathrm{NMR}\left(75 \mathrm{MHz}, \mathrm{CDCl}_{3}\right): \delta 176.3,165.4,146.2$, 137.1, 132.0, 128.3, 127.7, 127.5, 122.7, 118.1, 107.9, 94.9, 89.8, 81.9, 76.5, 73.5, 70.0, 68.0, 64.9, 59.5, 44.3, 41.7, 37.8, 28.7, 27.8, 20.3, -0.36; LRMS (EI): $\mathrm{m} / \mathrm{z} 554$.

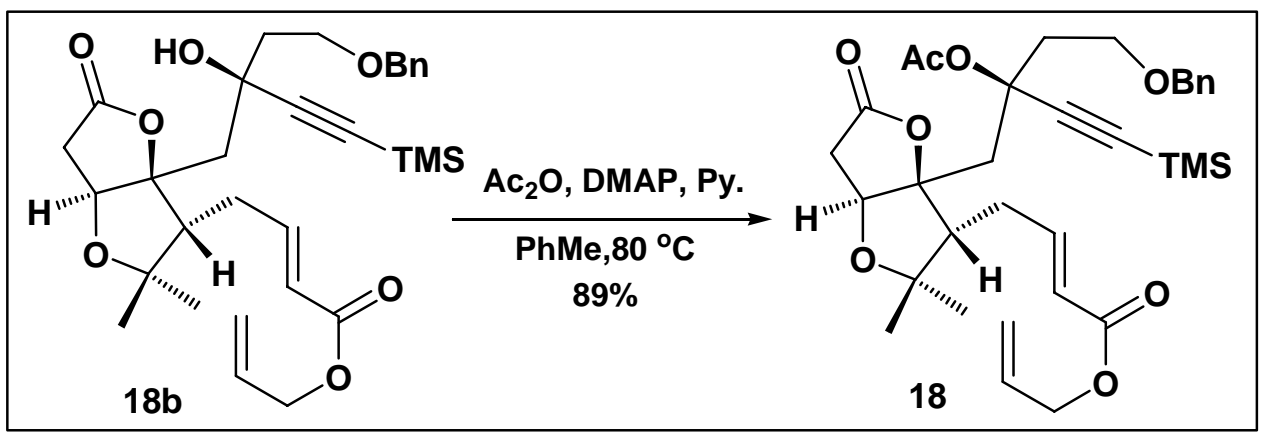

Compound 18: To the solution of acetylene alcohol $(0.315 \mathrm{~g}, 0.569 \mathrm{mmol})$ in toluene (10 $\mathrm{mL})$ was sequentially added $\mathrm{Ac}_{2} \mathrm{O}(0.533 \mathrm{ml}, 5.69 \mathrm{mmol})$, DMAP $(0.139 \mathrm{~g}, 1.137 \mathrm{mmol})$ and pyridine $(0.46 \mathrm{~mL}, 5.69 \mathrm{mmol})$, and the mixture was heated at $120{ }^{\circ} \mathrm{C}$ for $48 \mathrm{~h}$. After cooling down the room temperature, water $(5 \mathrm{~mL})$ was added and the mixture was extracted with EtOAc $(3 \times 10 \mathrm{~mL})$. The combined organic layers were washed with brine $(2 \times 5 \mathrm{~mL})$, and dried over $\mathrm{Na}_{2} \mathrm{SO}_{4}$. The solvent was removed under vacuum and the residue was purified by $\mathrm{SiO}_{2}$ flash chromatography (petroleum ether/ethyl acetate $=4 / 1)$ to give product 18 as a colorless oil $(0.301 \mathrm{~g}$, $89 \%)$.

${ }^{1}$ H-NMR $\left(300 \mathrm{MHz}, \mathrm{CDCl}_{3}\right): \delta$ 7.37-7.26 (m, 5H), 6.90-6.83 (m, 1H), 5.99-5.90 (m, 1H), 5.88-5.83 (d, $J=15.6 \mathrm{~Hz}, 1 \mathrm{H}), 5.37-5.35(\mathrm{~m}, 1 \mathrm{H}), 5.36-5.22(\mathrm{~m}, 2 \mathrm{H}), 4.65-4.58(\mathrm{~m}, 2 \mathrm{H})$, 4.51-4.47 (d, $J=11.4 \mathrm{~Hz}, 1 \mathrm{H}), 4.44-4.40(\mathrm{~d}, J=11.4 \mathrm{~Hz}, 1 \mathrm{H}), 3.78-3.72(\mathrm{~m}, 1 \mathrm{H}), 3.67-3.61(\mathrm{~m}$, 1H), 3.14-3.05 (m, 1H), 3.06-2.99 (d, $J=18.6 \mathrm{~Hz}, 1 \mathrm{H}), 2.66-2.60$ (d, $J=18.6 \mathrm{~Hz}, 1 \mathrm{H}), 2.58-2.50$ (m, 1H), 2.42-2.97 (m, 5H), 1.95 (s, 3H), 1.27 (s, 3H), 1.00 (s, 3H), 0.18 (s, 9H); ${ }^{13}$ C-NMR $\left(75 \mathrm{MHz}, \mathrm{CDCl}_{3}\right): \delta 175.6,169.2,165.4,145.9,137.9,132.1,128.3,127.6,126.9,122.9,118.0$, 103.4, 95.5, 93.3, 82.1, 76.3, 75.8, 73.1, 66.4, 64.9, 59.8, 41.6, 39.7, 37.3, 28.7, 27.9, 21.8, 20.1, -0.59; LRMS (EI): $\mathrm{m} / \mathrm{z} 596$. 


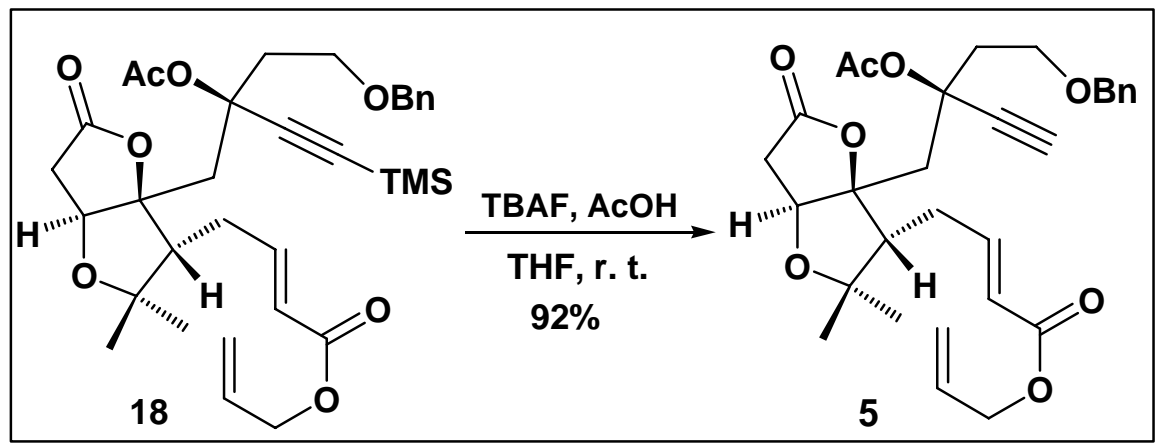

Compound 5: To a solution of compound $18(0.268 \mathrm{~g}, 0.45 \mathrm{mmol})$ in THF $(20 \mathrm{~mL})$ at room temperature was sequentially added $\mathrm{AcOH}(0.25 \mathrm{~mL}, 4.50 \mathrm{mmol})$ and $\mathrm{TBAF} \cdot 3 \mathrm{H}_{2} \mathrm{O}(0.284 \mathrm{~g}$, $0.90 \mathrm{mmol}$ ), and the mixture was stirred at the same temperature for $12 \mathrm{~h}$. The reaction was quenched with water $(5 \mathrm{~mL})$, and the mixture was extracted with ether $(3 \times 15 \mathrm{~mL})$. The combined organic layers were washed with brine $(2 \times 3 \mathrm{~mL})$, and dried over $\mathrm{Na}_{2} \mathrm{SO}_{4}$. The solvent was removed under vacuum and the residue was purified by $\mathrm{SiO}_{2}$ flash chromatography (petroleum ether/ethyl acetate $=2 / 1)$ to give product 5 as a colorless oil $(0.218 \mathrm{~g}, 92 \%)$.

${ }^{1}$ H-NMR $\left(300 \mathrm{MHz}, \mathrm{CDCl}_{3}\right): \delta$ 7.44-7.19 (m, 5H), 6.93-6.83 (m, 1H), 6.01-5.90 (m, 1H), 5.89-5.83 (d, $J=15.6 \mathrm{~Hz}, 1 \mathrm{H}), 5.37-5.20(\mathrm{~m}, 3 \mathrm{H}), 4.69-4.59(\mathrm{~m}, 2 \mathrm{H}), 4.50-4.46(\mathrm{~d}, J=11.7 \mathrm{~Hz}$, $1 \mathrm{H}), 4.45-4.42(\mathrm{~d}, J=11.7 \mathrm{~Hz}, 1 \mathrm{H}), 3.80-3.72(\mathrm{~m}, 1 \mathrm{H}), 3.66-3.60(\mathrm{~m}, 1 \mathrm{H}), 3.08-3.00$ (dd, $J=18.6$ $\mathrm{Hz}, 6.6,1 \mathrm{H}), 3.00-2.95(\mathrm{~d}, J=15.3 \mathrm{~Hz}, 1 \mathrm{H}), 2.76(\mathrm{~s}, 3 \mathrm{H}), 2.67-2.61(\mathrm{~d}, J=18.6 \mathrm{~Hz}, 1 \mathrm{H})$, 2.47-1.97 (m, 4H), $1.96(\mathrm{~s}, 3 \mathrm{H}), 1.25(\mathrm{~s}, 3 \mathrm{H}), 1.01(\mathrm{~s}, 3 \mathrm{H}) ;{ }^{13}$ C-NMR $\left(75 \mathrm{MHz}, \mathrm{CDCl}_{3}\right): \delta 175.5$, $169.2,165.4,145.8,137.8,132.1128 .3,127.7,127.6,122.9,118.0,95.2,82.2,82.1,76.5,75.9$, 75.6, 73.1, 66.1, 65.0, 59.8, 41.8, 39.7, 37.4, 28.7, 28.0, 21.8, 20.2; LRMS (EI): m/z 524. 